\title{
Circuit
}

Musiques contemporaines

\section{Le métier : l’acte musical}

\section{Gilles Tremblay}

Volume 5, numéro 1, 1994

\section{Gilles Tremblay : réflexions}

URI : https://id.erudit.org/iderudit/902081ar

DOI : https://doi.org/10.7202/902081ar

Aller au sommaire du numéro

Éditeur(s)

Les Presses de l'Université de Montréal

\section{ISSN}

1183-1693 (imprimé)

1488-9692 (numérique)

Découvrir la revue

\section{Citer cet article}

Tremblay, G. (1994). Le métier : l'acte musical. Circuit, 5(1), 9-9. https://doi.org/10.7202/902081ar

\section{Résumé de l'article}

La responsable de ce numéro a rassemblé une collection de quinze textes de réflexions du compositeur québécois Gilles Tremblay, réunis sous cinq thèmes : les aspects du métier de compositeur et la vie quotidienne; les liens nécessaires dont ils témoignent entre foi chrétienne et création musicale; l'environnement sonore actuel défini par la triologie « bruit-son-silence »; l'appartenance à " un pays à faire ", soulignant l'enrachinement culturel de l'artiste; et enfin, deux hommages à Serge Garant et Claude Vivier. Trois annexes présentant des repères biographiques avec le catalogue des œuvres, une liste des écrits du compositeur et une discographie complètent ce dossier. d'utilisation que vous pouvez consulter en ligne.

https://apropos.erudit.org/fr/usagers/politique-dutilisation/ 


\section{Gilles Tremblay: Écrits et entrevues}

\section{LE MÉTIER}

\section{L'acte musical $^{(1)}$}

Texte publié dans Le Devoir, 27 juin 1970 et in R. Duguay, Coffret G. Tremblay, op.cit., p. 289.

La vie quotidienne dans laquelle nous baignons est continuellement modelée par les événements, les moments, qui en ponctuent les cours, qui en tissent la durée. Exemple: lever de soleil, événement politique, coup de téléphone, danse de la neige, murmure de la foule, rencontre d'un regard.

A première vue, ces ensembles ne paraissent avoir aucun sens, absurdes même, bons simplement pour un inventaire. Pourtant, ils sont tendus de relations, de dynamismes, de mouvements, riches d'une variété inouĩe: créateurs de rythmes.

Le lever du soleil, l'événement politique, le chant de la cigale, celui de la cloche, l'éruption volcanique, le silence ne seront plus aussi étrangers les uns aux autres qu'ils auraient pu le paraître au premier abord. Pour le musicien, entendre, percevoir les relations musicales qui sont dans la vie, constitue déjà un acte musical. C'est pour lui, en tout cas, une attirance de plus en plus forte. Qu'il prolonge cet acte de réception unifiée en articulant l'œuvre aux musiques perçues que je viens d'évoquer et celle-ci entre dans une dimension toute nouvelle, nourrie par des mouvements qui la dépassent. Si l'œuvre aide l'auditeur à son tour à percevoir les musiques latentes qui nous entourent, alors le musicien sera comblé.
(1) L'auteur a formulé ces idées en 1965. A cet effet, il a déclaré : « Elles me sont de plus en plus présentes et actuelles, à travers, bien sûr des développements accrus, multipliés, et à venir : par leur nécessité poétique même . La création de Champs I, (1965, rev. 1969) pour piano et deux percussions a eu lieu en février 1965 à Montréal par l'Ensemble de percussions de Paris (Vincent Gémignani, Boris de Vinogradov, percussions et Claude Raynaud, piano). 